\title{
Beyond the Traditional Epidemiology of Risk Factors: Socioeconomic Inequity and Cultural Dimensions of Health-Disease Process
}

ISSN: 2689-2707

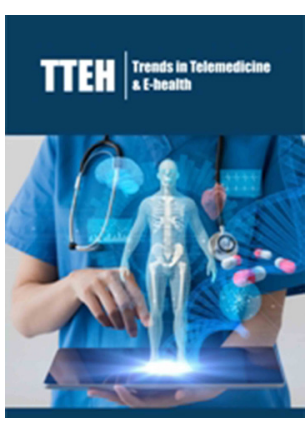

*Corresponding author: Marcos Bagrichevsky PhD, Department of Medicine, Regional University of Blumenau, Santa Catarina, Brazil E-mail: marcos_bagrichevsky@yahoo. com.br

Submission: 眥 December 14, 2019

Published: 眥December 19, 2019

Volume 2 - Issue 2

How to cite this article: Bagrichevsky M. Beyond the Traditional Epidemiology of Risk Factors: Socioeconomic Inequity and Cultural Dimensions of Health-Disease Process. Trends Telemed E-Health 2(2) TTEH. 000532. 2019.

DOI: 10.31031/TTEH.2019.02.000532

Copyright@ Marcos Bagrichevsky, This article is distributed under the terms of the Creative Commons Attribution 4.0 International License, which permits unrestricted use and redistribution provided that the original author and source are credited.

\author{
Marcos Bagrichevsky* \\ Department of Medicine, Regional University of Blumenau, Brazil
}

\author{
Abstract \\ Keyword: Risk factors; Epidemiology; Lifestyle; Socioeconomic inequity; Health-disease process
}

\section{Opinion}

Since the end of the twentieth century the epidemiological discourse has acquired a more and more undeniable value. This universal symbolic authority of epidemiology of risk factors has become emblematic with the incorporation of lifestyle rhetoric [1-3]. In advocating such an approach, the area has departed from its historical and epistemological assumptions (population and social context of illness) over the valuation of individual perspective inherent to the emergence of a new globalized economic order, which has gradually shifted the collective concerns of health public to a marginal position $[4,5]$ especially in peripheral capitalist countries [6].

Proposals subsidized by epidemiological inferences about risk behaviors, underestimate the macro-economic and political contexts of health problems and the subjective dimensions of social determinants of health-disease-care process [7]. Despite the undeniable heuristic value that epidemiology (descriptive) has accumulated so far, as a successful field in coping with human diseases over time, several questions are postulated to the epidemiology of risk factors - specific mote in criticism by researchers from the field itself [1,2].

Such approaches obscure the influence of social inequality in health care and are a preferred approach on how to think about certain health issues. The waiving of philosophical rigor/interpretive analysis of the sedentary lifestyle, smoking, alcohol consumption and obesity, considered epidemic behaviors and treated mainly as a result of "misguided personal choices" (risk lifestyles), has led to notions limited to a view by the subject isolated from their culture and from their potential interference on the public agenda [3]. Side effects of this ideology overflow in our postmodern informational society as a kind of moralizing pandemic [8].

If the profile of some epidemiological studies were resized, other interpretations might emerge as the so-called risk behaviors, such as in Mossakowski's research [9], to show that poverty and unemployment kept for a long time is represent risk factors for the use of heavy alcohol, regardless of gender, age, ethnicity or marital status. The mechanisms of individual and collective management of risks, contemporaneously embedded with our lives, relate to the profound and ambiguous structural changes in society $[3,7,10]$, where scientific information is gaining status of "self-imposed authority". Epidemiology cannot lose sight of that scenario and of the influence exercised by meanings, norms and socio-cultural values, prevailing in the specific ambience, which the researcher is part of [11]. 


\section{References}

1. Castiel LD (2004) What community? What lifestyle? J Epidemiol Community Health 58(11): 886.

2. Krieger N (2011) Epidemiology and the people's health: Theory and context. Oxford University Press, New York, USA.

3. Lupton D (1993) Risk as moral danger: The social and political functions of risk discourse in public health. Int J Health Services 23(3): 425-435.

4. Vahid SF, Sod-Erdene O, Ramraj C, Hildebrand V, Siddiqi A (2019) Government social assistance programs are falling to protect the health of low-income populations: Evidence from the USA and Canada (20032014). J Epidemiol Community Health 73(3): 198-205.

5. Navarro V (2009) What we mean by the social determinants of health. Int J Health Serv 39(3): 423-441.

6. Kind L, Ferreira-NJL (2013) Discourses and polarities concerning health promotion in the Brazilian health system. Salud Publica Mex 55(4): 427 432.
7. Gutiérrez JP, García SS, Espinosa PR, Balandrán DA (2016) Health inequalities on adolescent's risk behavior indicators in Mexico: Analysis of two national health surveys. Salud Publica Mex 58(6): 657-665.

8. Campos P, Saguy A, Ernsberguer P, Oliver E, Gaesser G (2006) The epidemiology of overweight and obesity: Public health crisis or moral panic? Int J Epidemiol 35(1): 55-60.

9. Mossakowski KN (2008) Is it duration of poverty and unemployment a risk factor for heavy drinking? Soc Sci Med 67(6): 947-955.

10. Kivits J, Laetitia R, Laetitia M (2019) Interdisciplinary research in public health: The why and how. J Epidemiol Community Health 73(12): 10611063.

11. Krieger N (2014) Got theory? On the $21^{\text {st }}$ c. CE rise of explicit use of epidemiologic theories of disease distribution: A review and Eco social analysis. Current Epidemiol Reports 1(1): 45-56. 